\title{
Development Of Joining Processes And Fabrication Of US First Wall Qualification Mockups For ITER
}

\author{
S.H. Goods ${ }^{1}$, J.D. Puskar ${ }^{2}$, R. M. Watson ${ }^{1}$ and M.A. Ulrickson ${ }^{2}$ \\ Sandia National Laboratories, ${ }^{1}$ Livermore, CA and ${ }^{2}$ Albuquerque, NM \\ shgoods@sandia.gov
}

\begin{abstract}
We report here the fabrication processes used to manufacture US Party Team First Wall Qualification Mockups along with the detailed microstructural characterization and mechanical properties of the $\mathrm{Be} / \mathrm{CuCrZr} / 316 \mathrm{~L}$ HIP bonds. A companion submission to this conference describes details of the PMTF heat flux testing and the performance of the first US FWQM.
\end{abstract}

Keywords-component; First Wall Qualification Mockup; ITER; HIP bonding

\section{INTRODUCTION}

The design of the ITER First Wall includes the use of S-65C beryllium $(\mathrm{Be})$ armor tiles as the plasma facing material joined to a $\mathrm{CuCrZr}(\mathrm{C} 18150)$ heat sink alloy, which in turn is bonded to a $316 \mathrm{~L}(\mathrm{~N})$ stainless steel $(\mathrm{SS})$ support structure. While the detailed design and operational characteristics of the ITER $1^{\text {st }}$ Wall continue to evolve, this material stack-up and the general requirements of the fabricated structure will remain unchanged.

The US ITER Party Team has identified Hot Isostatic Pressing (HIP) as the principal bonding process for the three materials that comprise the $1^{\text {st }}$ Wall. Definition of the specific manufacturing processes is constrained by the performance requirements of the $\mathrm{Be} / \mathrm{Cu}$ alloy and the $\mathrm{Cu}$ alloy/SS joints as well as by the mechanical property requirements of the precipitation hardenable copper alloy. Most attention has been focused on the character of the $\mathrm{Be} / \mathrm{Cu}$ alloy bond which is HIP processed at particularly low temperatures $\left(<600^{\circ} \mathrm{C}\right)$ in order to minimize strength loss in the $\mathrm{CuCrZr}$ alloy. However, new design considerations may require that the $\mathrm{Cu}$ alloy/stainless steel bond act as the primary pressure boundary for the pressurized cooling loop and this has resulted in an increased emphasis on the $\mathrm{Cu}$ alloy/SS joint properties and performance.

Starting in June 2007, the US ITER Party Team undertook the fabrication of two, First Wall Qualification Mockups (FWQM) for thermal fatigue testing. These structures would be subjected to a pre-defined thermal cycling regime simulating the expected heat flux loading of the ITER $1^{\text {st }}$ Wall. The successful completion of these tests forms the basis for acceptance, by the ITER IO, of the manufacturing processes proposed by the US. As of this writing, the first of the two US FQWM structures has successfully completed all thermal testing at Sandia/NM's Plasma Materials Test Facility (PMTF).

Sandia is a multiprogram laboratory operated by Sandia Corporation, a Lockheed-Martin Co., for the USDOE, under Contract \# DE-AC04-94AL8500

\section{FWQM DESIGN, MATERIALS AND HIP PROCESSING}

\section{A. First Wall Qualification Mockup}

Figure 1 shows the general features of the FWQM. The test article consists of a $316 \mathrm{~L}$ stainless steel base to which is initially HIP bonded a CuCrZr (C18150) precipitation hardenable heat sink alloy. For this application, the chromium content of the copper alloy is held to $0.6-0.9$ wt. $\%$ while the $\mathrm{Zr}$ content is called out as $0.07-0.15$ wt.\% with all other impurities as $<0.02$ wt.\%. Embedded in the copper alloy are $316 \mathrm{~L}$ stainless cooling tubes which are bonded to the heat sink and the base structure in this same step.

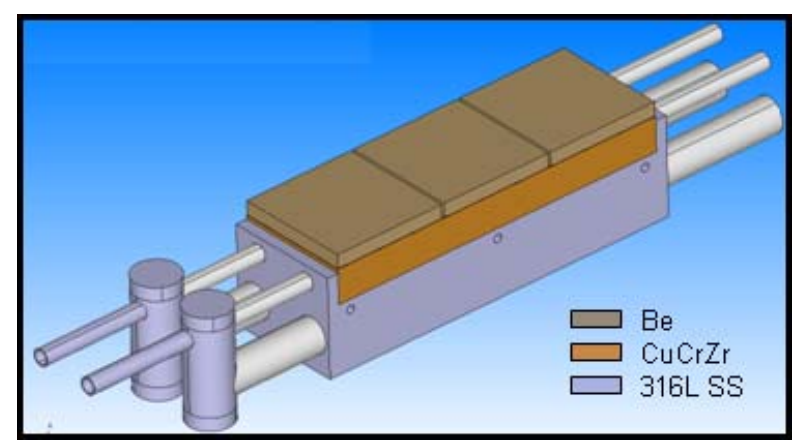

Figure 1. Artist's rendering of First Wall Qualification Mockup showing three $80 \mathrm{~mm}$ Be tiles bonded to a copper alloy substrate all bonded to a stainless steel base. Water cooling manifolds are shown as well.

A second, lower temperature, HIP bonded step joins three $80 \times 80 \mathrm{~mm}$, Brush-Wellman supplied, S-65C Be tiles to the top surface of the $\mathrm{CuCrZr}$. The tiles were cut from plates that were sectioned from powder consolidated ingots. These plates were cut parallel to the pressing direction of the Be ingot. The design of the mockup [1] is intended to mimic the thermal fatigue response of ITER First Wall panels.

\section{B. Surface conditioning for HIP bonding}

\section{1) $316 \mathrm{~L}$ Stainless Steel and $\mathrm{CuCrZr}$}

Surfaces of the stainless steel and copper alloy to be bonded were machined flat and ground to a surface finish of better than $0.8 \mu \mathrm{m}$. The ground stainless base and tubing were then caustic cleaned to remove oils and greases, rinsed in de-ionized water, isopropyl alcohol and blown dry with dry $\mathrm{N}_{2}$ gas. The 
machined copper alloy was solvent cleaned with acetone, chemically polished, rinsed and dried as described above.

\section{2) Beryllium tiles}

After machining and etching, the disks were vapor grit abraded to a surface finish of approximately $1 \mu \mathrm{m}$ RMS using alumina oxide media. These surfaces were then coated at a commercial vendor using argon ion sputter deposition (PVD) with a $2 \mu \mathrm{m}$ thick titanium layer and $25 \mu \mathrm{m}$ thick layer of copper. The metallization thicknesses were based on earlier work that optimized bond strength as it depended on film thickness and HIP processing temperatures [2].

\section{HIP Processing Conditions}

The first HIP bonding process that joins the $316 \mathrm{~L}$ stainless base to the copper (and the stainless cooling tubes to the copper and $316 \mathrm{~L}$ base) was performed at $1040^{\circ} \mathrm{C}, 103 \mathrm{MPa}$ for $2 \mathrm{~h}$. This is a particularly aggressive bonding temperature in that it is only $30^{\circ} \mathrm{C}$ below the onset of melting in the copper alloy and while not necessary to insure a metallurgically sound copper/stainless joint, was chosen in anticipation of the need to meet minimum toughness requirements for $316 \mathrm{~L} / 316 \mathrm{~L}$ joints per EU nuclear safety design codes. Pressure and temperature traces for the HIP bonding cycle are shown in Figure 2.

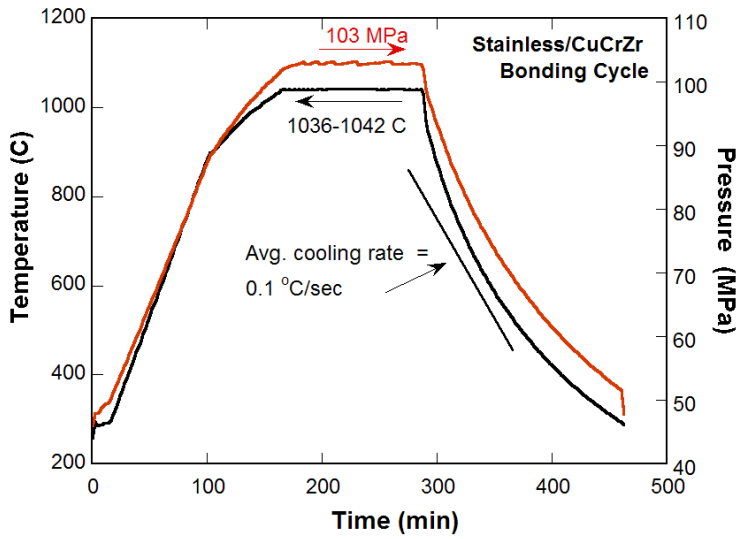

Figure 2. Temperature and pressure profile for high temperature HIP bonding cycle.

Because the thermal mass of the HIP autoclave is large, the average cooling rate from the bonding temperature is slow. In order to return the $\mathrm{CuCrZr}$ to its solutionized condition, it was necessary to anneal the still encapsulated HIP structure at $980^{\circ} \mathrm{C}$ for 40 minutes followed by a water quench.

The second HIP run (data trace not shown) bonds the Be tiles to the $\mathrm{Cu}$ alloy heat sink. Since the $\mathrm{CuCrZr}$ was returned to the fully solutionized condition, this HIP cycle precipitation hardens the alloy. Per ITER specification, the minimum yield strength requirement for the copper alloy is $175 \mathrm{MPa}$ at $25^{\circ} \mathrm{C}$. This strength requirement restricts the bonding temperature to temperatures $<600^{\circ} \mathrm{C}$, as any higher temperature would severely overage the material, reducing its strength to levels below the minimum allowable. In order to insure some margin in strength, the HIP bonding temperature was set at $560^{\circ} \mathrm{C}$. HIP pressure and time were equal to that used in the previous cycle, $103 \mathrm{MPa}$ and $2 \mathrm{~h}$, respectively.

\section{HIP Processing Sequence}

Assembly of the component piece parts are shown in Figure 3. Figure 3a shows the 316L stainless steel base upon which is mounted the lower half of the copper alloy insert and stainless steel cooling tubes. End-to-end the base measures approximately $280 \mathrm{~mm}$. Figure $3 \mathrm{~b}$ shows the upper half the copper insert in place. Figure $3 \mathrm{c}$ shows the HIP shroud which is GTA welded around its periphery to the steel base. The final weld closure is done using ebeam techniques in vacuum.

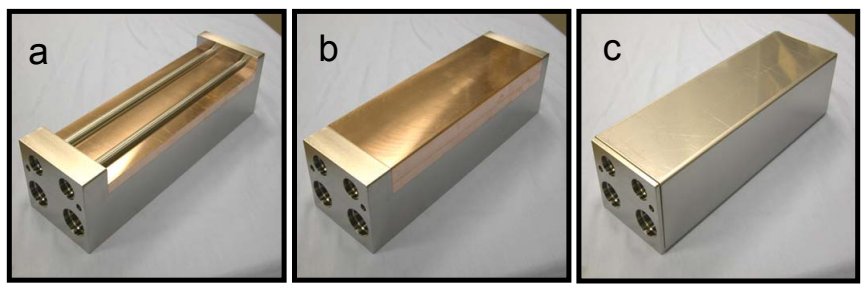

Figure 3. Assembly and encapsulation sequence for first HIP cycle

To prevent the HIP gas from collapsing the cooling tubes, the tube openings in the base face are interconnected to a machined hole in the bottom (not seen in the view presented) and end plugs are welded to close the tube openings. The enshrouded structure, shown in Figure 3c, is then HIP processed at $1040^{\circ} \mathrm{C}$ as described earlier. Since the cooling tubes shown in Figure 3a pass beyond the copper alloy insert into the stainless steel end faces, they are bonded simultaneously to the copper alloy and the base structure in this first HIP step.

Figure $4 \mathrm{a}$ shows the bonded $\mathrm{CuCrZr} / 316 \mathrm{~L}$ stainless steel assembly after HIP processing and solution annealing. The shroud has been removed and the copper alloy surface has been machined and prepared to accept the metallized Be tiles. Figure
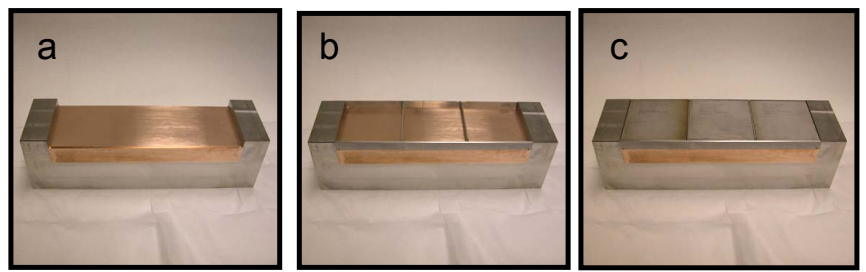

Figure 4. Assembly and encapsulation sequence for second HIP cycle

4b shows a stainless steel tile alignment structure fixtured to the copper alloy surface and Figure 4c shows the tiles positioned in the alignment structure. The entire assembly is then enshrouded in a manner similar to that shown in Figure $3 \mathrm{c}$ and HIP processed at $560^{\circ} \mathrm{C}$.

\section{STRUCTURE AND PROPERTIES OF HIP JOINTS}

\section{A. $\quad \mathrm{CuCrZr/316L} \mathrm{Stainless} \mathrm{HIP} \mathrm{bond}$}

A witness structure consisting of all three materials (S-65C, $\mathrm{CuCrZr}$, 316L SS) was processed under conditions identical to that of the FWQM's. Mechanical test specimens and coupons for microstructural characterization were extracted from this structure. Figure 5 shows representative tensile curves for specimens extracted from across the bondline. ITER IO specifications require that the bond strength exceed that of either material and that the copper alloy yield strength exceed 
$175 \mathrm{MPa}$. The figure reveals that the yield strength exceeded $200 \mathrm{MPa}$ and tensile fracture always occurred in the copper alloy (see tensile specimen insert in Figure 5), well away from the bondline itself, satisfying both requirements. Variability in

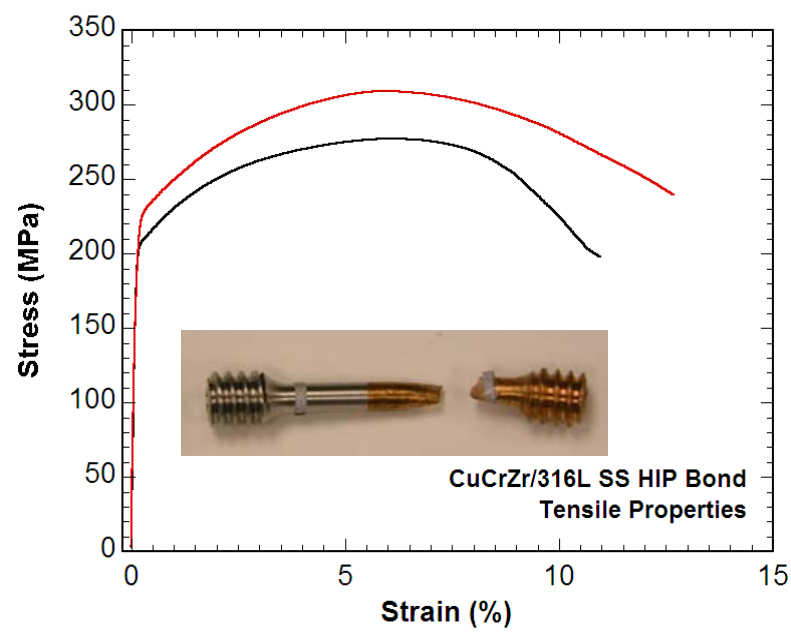

Figure 5. Tensile behavior of CuCRZr/316L HIP bond

strength was likely the result of the very coarse grain size of the copper, a consequence of the very high initial HIP processing temperature. Additional testing performed on specimens extracted from within the $\mathrm{CuCrZr}$ confirmed that yield and UTS minimums were met at both $25^{\circ} \mathrm{C}$ and $250^{\circ} \mathrm{C}$.

Figure 6 shows a metallographically prepared cross-section of the HIP processed copper alloy/stainless steel joint. Because of the high bonding temperature, interdiffusion rates of the constituent elements of the copper alloy and stainless steel are high and the resulting microstructure of the $\mathrm{CuCrZr} / 316 \mathrm{~L} \mathrm{SS}$

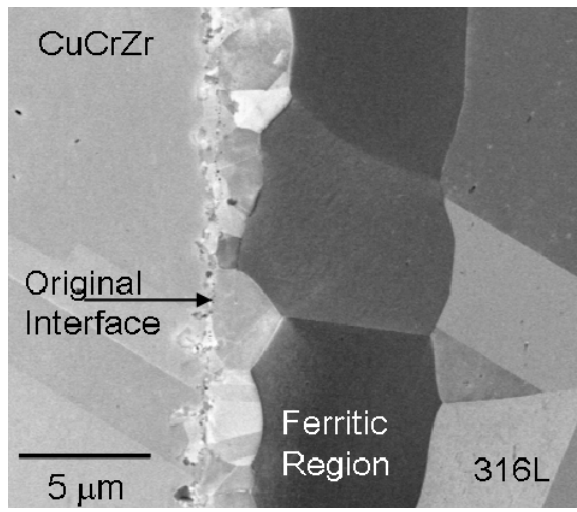

Figure 6. Scanning electron micrograph of $\mathrm{CuCrZr} / 316 \mathrm{~L}$ HIP bond

bond is complex. The figure shows the copper alloy to the left and the $316 \mathrm{~L}$ stainless steel base to the right. The original interface is labeled and appears to be decorated with fine particles. Elemental maps for copper and zirconium derived from energy dispersive spectroscopy (EDS) are shown in Figure 7. Within this very narrow region, the map for zirconium shows discreet features of very high concentration. Immediately to the right of the original interface and abutting the steel is a region of nearly pure copper.
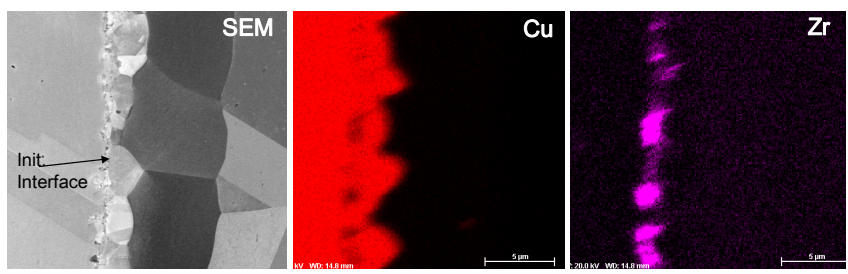

Figure 7. EDS derived elemental maps for copper and zirconium of the copper alloy/stainless steel bond.

The composition of the near interface region was further examined via electron microprobe analysis (EMP). Figure 8 shows the distribution of the principal alloying elements of both the copper and stainless steel across the bondline. As the maximum ordinate value is 40 at.\%, the peak copper and iron distribution away from the bondline are not shown. The EMP

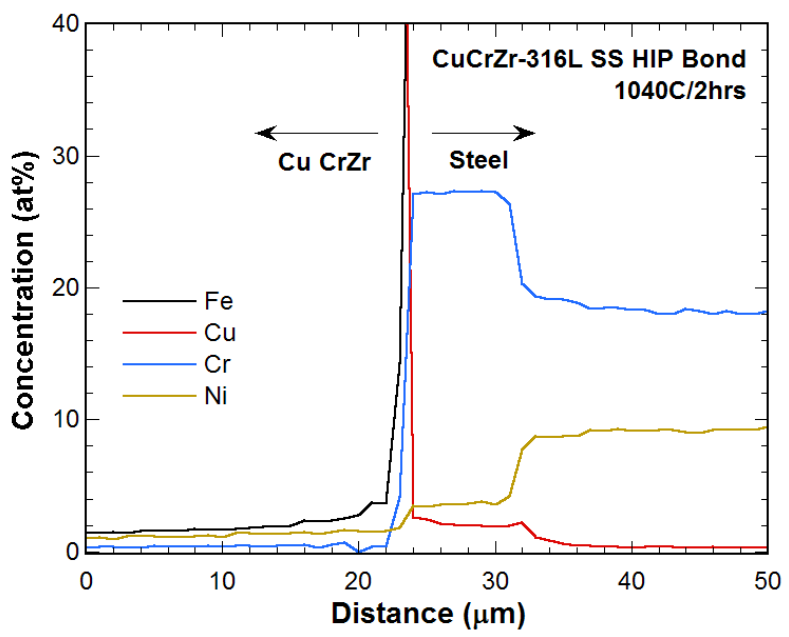

Figure 8. EMP traces across $\mathrm{CuCrZr}$ /stainless steel bond shown in Figure 6 .

results reveal that nickel in the stainless steel is depleted from the baseline concentration of 9.5 at $\%$ to less than 4 at $\%$. It is this depletion in $\mathrm{Ni}$ concentration that is responsible for the transformation from the FCC austenitic structure to the $\mathrm{BCC}$ ferritic structure. Iron diffusion into the copper alloy as well as copper diffusion into the steel is also evident.

\section{B. $\mathrm{Be} / \mathrm{CuCrZr} \mathrm{HIP}$ bond}

Tensile and shear strengths of the $\mathrm{Be} / \mathrm{CuCrZr}$ HIP bond $\left(560^{\circ} \mathrm{C}, 103 \mathrm{MPa}, 2 \mathrm{~h}\right)$ were characterized by using EDM techniques to extract specimens from the witness structure. In the former case, flat dogbone specimens were machined from across the interface while in the latter instance, a modified shear specimen following ASTM A263 was used. Results are shown in Figure 9a for the tensile tests and Figure $9 b$ for the shear tests. For the six samples tested, tensile fracture ranged between 140 and $225 \mathrm{MPa}$ with an average fracture stress of $190 \mathrm{MPa}$ and a standard deviation of $40 \mathrm{MPa}$. Since the fracture strength is generally below the yield strength of the $\mathrm{CuCrZr}$ and below that of the S-65C beryllium [3] little or no ductility is realized in tension. With respect to shear strength, 

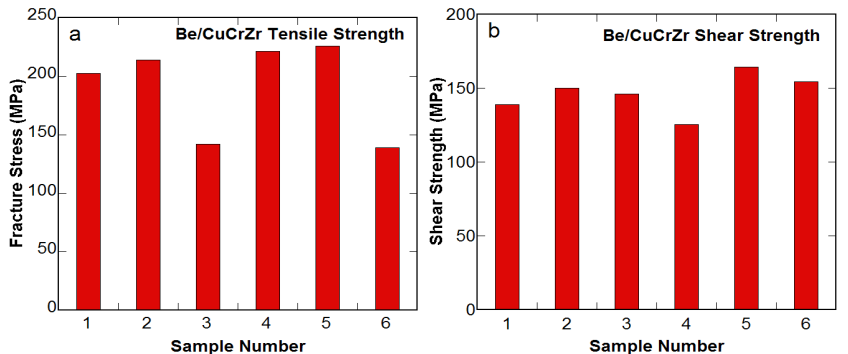

Figure 9. a) Tensile fracture strength and b) shear strength of the $\mathrm{Be} / \mathrm{CuCrZr}$ bond HIP processed at $560^{\circ} \mathrm{C}, 103 \mathrm{MPa}, 2 \mathrm{~h}$.

measurements ranged between 125 and $164 \mathrm{MPa}$ with an average shear strength of $146 \mathrm{MPa}$ and a standard deviation of 13.4 MPa.

Metallographic cross-sections of the $\mathrm{Be} / \mathrm{CuCrZr}$ HIP bond were prepared and Figure 10 shows a backscatter electron (BES) image. In BES mode, contrast is related to atomic mass, $\mathrm{Z}$. Low $\mathrm{Z}$ elements such as $\mathrm{Be}$ (the rightmost region in Figure 10) appear dark. The large, nearly round features within the region labeled $\mathrm{CuCrZr}$ are long, rod-like, $\mathrm{Cr}$-rich precipitates (seen end on in this view) and their presence is useful for identifying the boundary between the copper alloy

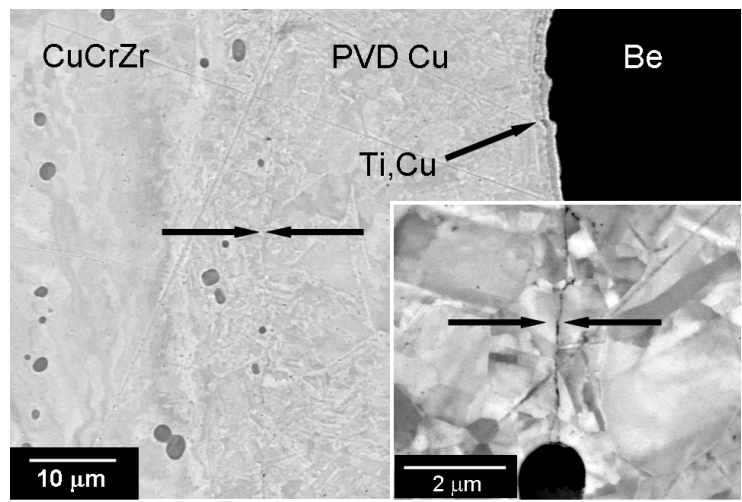

Figure 10. BES image of $\mathrm{Be} / \mathrm{CuCrZr}$ bondline.

and the PVD copper film deposited on the Be tile. The arrows near the center of the micrograph point to the initial physical interface between the $\mathrm{CuCrZr}$ and the PVD copper film. The inset in Figure 10 shows this feature at higher magnification and the initial physical interface is more apparent. The similarity in the grain morphology on either side of the interface is somewhat surprising given the very different origin of the materials (wrought $\mathrm{CuCrZr}$ vs. PVD $\mathrm{Cu}$ ). Also highlighted is a thin boundary layer abutting the Be tile labeled $\mathrm{Ti}, \mathrm{Cu}$.

Figure 11 shows the detailed structure of this interface region between the $\mathrm{Be}$ tile surface and the $\mathrm{Ti}$ and $\mathrm{Cu}$ metallization films. The arrows point to two layers of complex grain structures separating the PVD copper from the Be tile. Previous work [2] identified these layers as having discrete stoichiometries corresponding to the intermetallic compounds $\mathrm{CuTi}$ and $\mathrm{CuTi}_{2}$ which form during the $560^{\circ} \mathrm{C}$ HIP step.

Lastly, a completed mockup is shown in Figure 12.

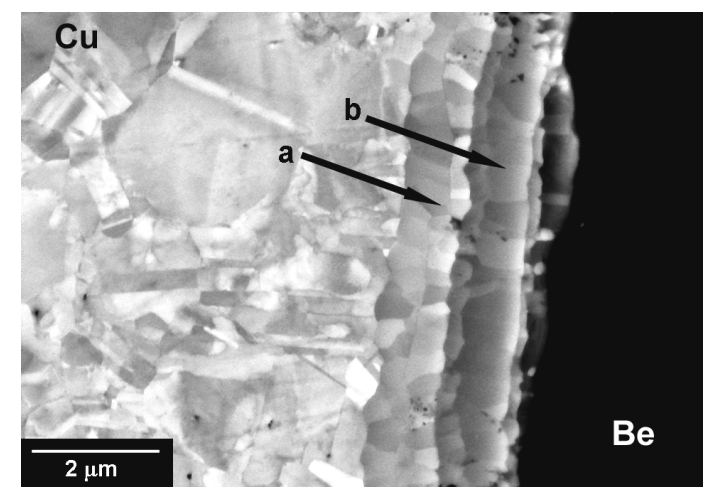

Figure 11. BES image of metaliization film/Be interface

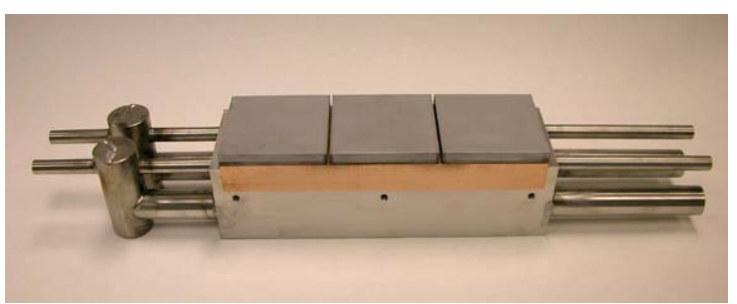

Figure 12. Completed First Wall Qualification Mockup

\section{SUMMARY}

The US ITER Party Team has successfully manufactured and delivered two First Wall Qualification Mockups for testing. Processing parameters for the $\mathrm{Be} / \mathrm{CuCrZr} \mathrm{HIP}$ bond (in particular, the Ti metallization thickness and HIP bonding temperatures) were established during an earlier R\&D program. In conjunction with a solutionizing treatment between the high temperature $\mathrm{Cu} / \mathrm{SS}$ bonding cycle and the lower temperature $\mathrm{Be} / \mathrm{CuCrZr}$ bonding cycle, the $\mathrm{CuCrZr}$ heat sink alloy met the strength and ductility minimums set by the ITER IO

\section{ACKNOWLEDGMENT}

The authors acknowledge the contributions of colleagues at Sandia National Laboratories, in particular R.M. Watson, G.R Gibbs, A.L. Newman and B.B. McKenzie for their assistance in the fabrication and analysis of the mockups. External collaborators include: Entegris Specialty Coatings, Kittyhawk Products, Synertech P/M, and The Peregrine-Falcon Corp.

\section{REFERENCES}

[1] V. Barabash and P. Chappuis, "Specification for manufacturing of first wall qualification mockups", Document ID: ID ITER_D_24KTBS v2.0, 2008

[2] J. D. Puskar, S. H. Goods, C. H. Cadden, "Diffusion bonding of beryllium to $\mathrm{CuCrZr}$ for ITER applications", Trends in Welding Research: Proceedings of the 9th International Conference, ASM International (to be published)

[3] S.H.Goods and D.E. Dombrowski, "Mechanical Properties Of S-65C Grade Beryllium at Elevated Temperatures", SAND98-8400, Sandia National Laboratories, 1997. 